\title{
Empirical use of antibiotics and adjustment of empirical antibiotic therapies in a university hospital: a prospective observational study Julian Mettler ${ }^{1}$, Mathew Simcock ${ }^{1,2}$, Pedram Sendi1,2, Andreas F Widmer ${ }^{1}$, Roland Bingisser ${ }^{3}$, Manuel Battegay ${ }^{1}$, Ursula Fluckiger ${ }^{1}$ and Stefano Bassetti*1,4
}

Address: ${ }^{1}$ Division of Infectious Diseases \& Hospital Epidemiology, University Hospital Basel, CH - 4031 Basel, Switzerland, ${ }^{2}$ Basel Institute for Clinical Epidemiology, University Hospital Basel, CH - 4031 Basel, Switzerland, ${ }^{3}$ Emergency Department, University Hospital Basel, CH - 4031 Basel, Switzerland and ${ }^{4}$ Department of Internal Medicine, Kantonsspital Olten, Baslerstrasse 150, CH - 4600 Olten, Switzerland

Email: Julian Mettler - MettlerJ@uhbs.ch; Mathew Simcock - SimcockM@uhbs.ch; Pedram Sendi - Pedram.Sendi@unibas.ch; Andreas F Widmer - WidmerA@uhbs.ch; Roland Bingisser - BingisserR@uhbs.ch; Manuel Battegay - BattegayM@uhbs.ch;

Ursula Fluckiger - FlueckigerU@uhbs.ch; Stefano Bassetti* - sbassetti_ol@spital.ktso.ch

* Corresponding author

Published: 26 March 2007

BMC Infectious Diseases 2007, 7:21 doi:10.1186/147I-2334-7-2I
Received: 9 May 2006

Accepted: 26 March 2007

This article is available from: http://www.biomedcentral.com/l47I-2334/7/2I

(c) 2007 Mettler et al; licensee BioMed Central Ltd.

This is an Open Access article distributed under the terms of the Creative Commons Attribution License (http://creativecommons.org/licenses/by/2.0), which permits unrestricted use, distribution, and reproduction in any medium, provided the original work is properly cited.

\begin{abstract}
Background: Several strategies to optimise the use of antibiotics have been developed. Most of these interventions can be classified as educational or restrictive. Restrictive measures are considered to be more effective, but the enforcement of these measures may be difficult and lead to conflicts with prescribers. Any intervention should be aimed at targets with the highest impact on antibiotic prescribing. The aim of the present study was to assess the adequacy of empirical and adjusted antibiotic therapies in a Swiss university hospital where no antibiotic use restrictions are enforced, and to identify risk factors for inadequate treatment and targets for intervention.
\end{abstract}

Methods: A prospective observational study was performed during 9 months. All patients admitted through the emergency department who received an antibiotic therapy within 24 hours of admission were included. Data on demographic characteristics, diagnoses, comorbidities, systemic inflammatory response syndrome (SIRS) parameters, microbiological tests, and administered antibiotics were collected prospectively. Antibiotic therapy was considered adequate if spectrum, dose, application modus, and duration of therapy were appropriate according to local recommendations or published guidelines.

Results: 2943 admitted patients were evaluated. Of these, 572 (19.4\%) received antibiotics within 24 hours and 539 (94\%) were analysed in detail. Empirical antibiotic therapy was inadequate in 121 patients (22\%). Initial therapy was adjusted in 168 patients (31\%). This adjusted antibiotic therapy was inadequate in 46 patients $(27 \%)$. The main reason for inadequacy was the use of antibiotics with unnecessarily broad spectrum (24\% of inadequate empirical, and $52 \%$ of inadequate adjusted therapies). In $26 \%$ of patients with inadequate adjusted therapy, antibiotics used were either ineffective against isolated pathogenic bacteria or antibiotic therapy was continued despite negative results of microbiological investigations.

Conclusion: The rate of inadequate antibiotic therapies was similar to the rates reported from other institutions despite the absence of a restrictive antibiotic policy. Surprisingly, adjusted antibiotic therapies were more frequently inappropriate than empirical therapies. Interventions aiming at improving antibiotic prescribing should focus on both initial empirical therapy and streamlining and adjustment of therapy once microbiological results become available. 


\section{Background}

Antibiotic resistance of bacteria is an increasing, worldwide problem [1-3]. The use of antibiotics is an important factor contributing to the emergence of antibiotic-resistant bacteria $[4,5]$, and it is well known, that a large proportion of administered antibiotics is prescribed without proper indication [6-11]. Published rates of inappropriate antibiotic use are as high as $41 \%$ to $91 \%[6,11]$.

Several strategies to optimise the use of antibiotics, often referred to as antibiotic stewardship programs, have been developed. These interventions can be classified into two main categories: educational, and restrictive or coercive [12]. Both types of intervention may be useful in reducing the amount of prescribed antibiotics and costs of therapy while maintaining quality of care $[13,14]$. However, restrictive measures are considered to be more effective and to have a longer lasting impact than educational strategies [12].

The aim of the present study was to assess the adequacy of empirical and adjusted antibiotic therapies at a Swiss university hospital where no restrictive measures regarding antibiotic use are in place, and to identify risk factors for inadequate treatment and targets for intervention.

\section{Methods}

The study was conducted prospectively during a period of 9 months (November 17, 2003 - July 31, 2004) on alternating weeks at the University Hospital Basel, a 700-bed hospital in Northwestern Switzerland providing primary and tertiary care for adult patients. The emergency department of this hospital handles all emergencies except gynecological/obstetrical, ophthalmologic and pediatric ones. In $2004,38.5 \%$ of all in-patients were admitted through the emergency department.

Antibiotics available within the hospital are listed in the drug formulary. All drugs included in the formulary can be prescribed without restrictions. In addition, the hospital pharmacy provides drugs which are not in the formulary upon request, although physicians are encouraged to use listed agents. Written local recommendations for the antibiotic treatment of the most common infectious diseases are available to all hospital physicians on the intranet and as a booklet. These internal guidelines include recommendations on diagnosis and treatment of pneumonia, sepsis, endocarditis, urinary tract infections, infections of the central nervous system, intravascular catheter-related infections, fever in neutropenic patients, and on empirical therapy in patients with suspected infection. The guidelines focus mainly on the choice and on the dose of the antibiotic. Recommendations on duration of therapy (and on duration of i.v. therapy) are provided for some indications (e.g. endocarditis, meningitis, intra- vascular catheter-related infections, urinary tract infections). There are no general recommendations for the switch from i.v. to p.o. An active infectious diseases consultation service is present in the hospital and has a close collaboration with the microbiology laboratory. In addition, weekly infectious diseases rounds are held on all medicine wards, on the bone marrow transplant unit and on the intensive care units.

All patients admitted to the University Hospital Basel through the emergency department during the mentioned period were included in the study and prospectively followed-up for the use of therapeutic antibiotics. Data of all patients receiving an antibiotic therapy within 24 hours of admission were further analysed. These patients began an antibiotic treatment within 24 hours of admission or continued an antibiotic treatment started in another hospital. They were treated as in-patients on the emergency department ward, or transferred to the departments of internal medicine (including neurology and geriatrics), surgery, or to an intensive care unit, either directly after admission, or subsequently from the emergency department ward. The following patients were excluded: patients admitted to the eight-bed acute psychiatric intervention unit, to dermatology, ophthalmology, gynecology/obstetrics, or otorhinolaryngology wards; patients given antibiotics for prophylaxis or for Helicobacter pylori eradication; patients who started antibiotic therapies as out-patients and patients transferred to another hospital within 48 hours of admission.

Information on demographics, admission diagnoses, empirical and adjusted antibiotic therapies, duration of therapy, specimens submitted for bacteriological testing, results of microbiological investigations, involvement of infectious diseases consultants, Charlson comorbidity index [15], McCabe index [16] and systemic inflammatory response syndrome (SIRS) parameters were prospectively recorded on a standardised case report form. After discharge, all prospectively collected data were verified and completed by chart review. In addition, data on microbiological investigations were retrieved from the microbiology lab's internal computer system. Each case report form with the corresponding chart was reviewed together by two of the authors (J.M., S.B.), who assessed the adequacy of empirical and adjusted antibiotic therapy by consensus. Prescribing was reviewed daily and the appropriateness of the antibiotic, the dose and route of administration were assessed at any time during the course of therapy.

The empirical antibiotic therapy was defined as the initial antibiotic regimen started within 24 hours of admission. The adjusted antibiotic therapy was the antibiotic regimen after the first change of antibiotic substance. The switch of 
the same antibiotic from i.v. to p.o. was not considered to be an adjustment of therapy. Finally, we defined an antibiotic therapy as inadequate when one or more of the following points were not in accordance with local written recommendations or published guidelines (e.g. The Sanford Guide to Antimicrobial Therapy, practice guidelines of the Infectious Diseases Society of America): spectrum, dosage, application modus of antibiotics, or the duration of therapy, and/or when pathogenic bacteria that were resistant to the antibiotic used were isolated. If the application modus was considered to be not appropriate, the reason was recorded as "insufficient dosage" (e.g. if a patient with catheter-related bloodstream infection caused by $S$. aureus was treated with amoxicillin/clavulanate p.o.), or "excessive dosage" (e.g. if a patient with uncomplicated pneumonia caused by susceptible $S$. pneumoniae was kept on penicillin i.v.).

\section{Statistical Methods}

For the univariate analyses, t-tests between continuous variables and Chi-squared tests (or Fisher's Exact tests when appropriate) between categorical variables were used. All associations found to be statistically significant at the $25 \%$ significance level in the univariate analysis were collectively considered for the multivariate analysis to produce a model for both the empirical antibiotic therapy and adjusted antibiotic therapy separately. The multivariate analysis used a logistic regression model with an underlying binomial distribution with the Logit link. The goodness of fit of the model was assessed with the Log likelihood ratio test. The covariates considered for the empirical antibiotic therapy multivariate analysis were gender, age, neurological ward, involvement of infectious disease consultants, renal failure, use of broad-spectrum antibiotics, and superficial skin infections. For the adjusted antibiotic therapy multivariate analysis the following were considered: switch of antibiotic therapy due to bacteriological lab results, involvement of infectious disease consultants and patients with respiratory tract infections; however, none of these variables were found to be of importance in the final model. Confounders and plausible interactions considered were found not to be statistically significant for entry into the model. All statistical analyses were carried out using SAS version 8.2 (SAS Institute Inc., Cary, NC, USA).

The study was approved by the Research Ethics Committee of the Cantons Basel-Stadt and Basel-Land (N. 226/ 03).

\section{Results}

During the nine-month study period a total of 7792 patients were admitted to the University Hospital Basel through the emergency department. Of these patients,
3387 were admitted during the weeks when the study was carried out. Referral to another hospital within 48 hours after admission led to the exclusion of 224 patients. Referral to the psychiatry, dermatology, gynecology/obstetrics or otorhinolaryngology wards led to the exclusion of 88 patients, and 132 patients were excluded since they were given therapeutic antibiotics prior to admission in an outpatient setting (all these 132 patients had received antibiotics p.o.). A total of 572 of the remaining 2943 patients $(19.4 \%)$ were given therapeutic antibiotics within 24 hours after admission. Incomplete or missing records led to the exclusion of 33 patients. The remaining 539 patients (94.2\%) were analyzed. Data on demographics, infectious diseases diagnosed on admission, and the service in charge of these patients are presented in Table 1.

\section{Bacteriological investigations}

Within 48 hours of admission a total of 716 bacteriological samples were taken from 438 patients (81.3\%). The most commonly performed investigations were blood cultures (333 patients, $61.8 \%$ of all patients), urine cultures $(181,33.6 \%)$ and cultures of sputum or bronchoalveolar lavage $(86,16.0 \%)$. Two-hundred and fourteen pathogenic bacterial isolates were identified in 183 patients. The most common were Escherichia coli (64 patients, 12\%), Staphylococcus aureus (27 patients, 5\%), Streptococcus pneumoniae (23 patients, 4\%), Klebsiella pneumoniae (12 patients, 2.2\%), Haemophilus influenzae (9 patients, 1.7\%) and Pseudomonas aeruginosa (9 patients, $1.7 \%)$.

\section{Antibiotic therapies}

The most commonly used antibiotic for both empirical and adjusted therapy was amoxicillin/clavulanate (Table 2). Broad-spectrum antibiotics (cefepime, imipenem, meropenem, piperacillin/tazobactam) or vancomycin were initially administered to 95 patients $(17.6 \%)$. Empirical antibiotic therapies lasted a mean of 7.5 days after admission. $421(83.7 \%)$ patients received at least one antibiotic intravenously. Empirical intravenous antibiotics were switched to oral administration a median of 4 days after admission (range: 0 - 43; Interquartile range: $3)$. The empirical therapy was adjusted in 168 patients (31.2\% of all included patients) (Table 2). Of these, 65 patients $(38.7 \%)$ had their antibiotics switched because of bacteriological results.

Empirical antibiotic therapy was inadequate in 121 patients $(22.4 \%)$ and the adjusted antibiotic therapy was inadequate in 46 of 168 patients $(27.4 \%)$. In both empirical and adjusted antibiotic therapy the most common reason for inadequacy was the use of antibiotics with a too broad spectrum (Table 3 ). The second most common reason for inadequate adjusted therapy was the use of antibiotics ineffective against isolated pathogenic bacteria or 
Table I: Characteristics of the 539 included patients.

\begin{tabular}{|c|c|c|}
\hline Characteristic & Number of patients $(n=539)$ & Percentage of all patients \\
\hline Males & 297 & $55.1 \%$ \\
\hline Age in years (median; range) & $69[17-100]$ & \\
\hline 17 to 40 years & 96 & $17.8 \%$ \\
\hline 41 to 60 years & 104 & $19.3 \%$ \\
\hline More than 60 years & 339 & $62.9 \%$ \\
\hline \multicolumn{3}{|l|}{ Ward a } \\
\hline Medicine and geriatrics & 359 & $66.6 \%$ \\
\hline Surgery & 173 & $32.1 \%$ \\
\hline Medical intensive care & 25 & $4.6 \%$ \\
\hline Surgical intensive care & 10 & $1.9 \%$ \\
\hline Neurology & 4 & $0.7 \%$ \\
\hline \multicolumn{3}{|l|}{ Main infectious disease diagnosis upon admission } \\
\hline Respiratory tract infections & 169 & $31.4 \%$ \\
\hline Urinary tract infections, prostatitis, epididimytis & 113 & $21.0 \%$ \\
\hline Gastrointestinal infections b & 81 & $15.0 \%$ \\
\hline Skin and soft tissue infections & 42 & $7.8 \%$ \\
\hline Biliary tract infections & 25 & $4.6 \%$ \\
\hline Suspected systemic infections without identified focus ${ }^{c}$ & 25 & $4.6 \%$ \\
\hline Sepsis d & 22 & $4.1 \%$ \\
\hline Bone and joint infections & 17 & $3.2 \%$ \\
\hline Ear, nose and throat infections & 15 & $2.8 \%$ \\
\hline Central nervous system infections & 11 & $2.0 \%$ \\
\hline Neutropenic fever & 10 & $1.9 \%$ \\
\hline Other & 5 & $0.9 \%$ \\
\hline No infectious disease diagnosis & 4 & $0.7 \%$ \\
\hline Total number of patients with SIRS e & 256 & $47.5 \%$ \\
\hline Charlson comorbidity index [15] (mean +/-SD) & $2.4(+/-2.3)$ & \\
\hline McCabe index [16] - not fatal & 443 & $82.2 \%$ \\
\hline McCabe index - fatal $<5$ years & 64 & $11.9 \%$ \\
\hline McCabe index - fatal $<6$ months & 32 & $5.9 \%$ \\
\hline Died in hospital & 31 & $5.8 \%$ \\
\hline
\end{tabular}

a If patients were on more than one ward, each ward was counted separately.

$\mathrm{b}$ Includes gastroenteritis, diverticulitis, peritonitis, enterocolitis, appendicitis, abdominal abscess, acute abdomen.

c These patients did not meet the criteria of the sepsis definition.

d Sepsis: defined as clinical evidence of infection, plus SIRSe.

e Systemic inflammatory response syndrome (SIRS): includes two or more of the following: temperature $>38^{\circ} \mathrm{C}$ or $<36^{\circ} \mathrm{C}$, heart rate $>90$ beats per minute, leukocytes $>12,000 / \mu \mathrm{L}$ or $<4,000 / \mu \mathrm{L}$ (band forms were not routinely determined and were therefore not considered), respiratory rate $>20$ per minute.

against bacteria to be expected according to the postulated infections, or the continuation of antibiotic therapy even after negative cultures ruled out an infection (e.g. in the case of assumed urinary tract infections).

\section{Risk factors for inadequate antibiotic therapy}

The univariate analysis of characteristics of patients receiving adequate or inadequate therapy is presented in Tables 4 and 5. In the multivariate analysis, inadequate empirical antibiotic treatment was associated with female sex (odds ratio for adequate treatment: $0.47,95 \%$ confidence interval 0.31-0.72), no infectious disease diagnosis (OR 0.08, 95\% CI 0.01-0.78), the use of antibiotic therapies containing vancomycin or broad-spectrum antibiotics (cefepime, imipenem, meropenem, piperacillin/tazobactam) (OR 0.42, 95\% CI 0.26-0.70) and the presence of renal failure (OR $0.58,95 \%$ CI $0.36-0.92$ ). Adequate adjusted antibiotic treatment was associated with antibiotic switch due to bacteriological results (OR 5.13, 95\% CI 2.13-12.37).

\section{Discussion}

The main findings of this study were that I) $19 \%$ of patients admitted through the emergency department received antibiotics empirically. II) Empirical antibiotic therapy was inadequate in $22 \%$ and adjusted antibiotic therapy in $27 \%$ of cases. III) The main reason for inadequacy was the use of antibiotics with an unnecessarily 
Table 2: Most frequently used empirical and adjusted antibiotic therapies

\begin{tabular}{|c|c|c|}
\hline Type of therapy & Number of patients & $\%$ \\
\hline Empirical antibiotic therapies & 539 & $100 \%$ \\
\hline Amoxicillin/clavulanate & 223 & $41.4 \%$ \\
\hline Ciprofloxacin & 88 & $16.3 \%$ \\
\hline Piperacillin/tazobactam & 55 & $10.2 \%$ \\
\hline Amoxicillin/clavulanate + clarithromycin & 33 & $6.1 \%$ \\
\hline Ceftriaxone & 23 & $4.3 \%$ \\
\hline Cefepime + amikacin & 18 & $3.3 \%$ \\
\hline Amoxicillin/clavulanate + amikacin & 12 & $2.2 \%$ \\
\hline Ciprofloxacin + metronidazole & 9 & $1.7 \%$ \\
\hline Trimethoprim/sulfamethoxazole & 6 & $1.1 \%$ \\
\hline Norfloxacin & 6 & $1.1 \%$ \\
\hline Cefepime & 5 & $0.9 \%$ \\
\hline Ceftriaxone + clarithromycin & 5 & $0.9 \%$ \\
\hline Other antibiotics or antibiotic combinations & 56 & $10.4 \%$ \\
\hline Adjusted antibiotic therapies & 168 & $100 \%$ \\
\hline Amoxicillin/clavulanate & 29 & $17.3 \%$ \\
\hline Piperacillin/tazobactam & 22 & $13.1 \%$ \\
\hline Ciprofloxacin & 15 & $8.9 \%$ \\
\hline Penicillin & 12 & $7.1 \%$ \\
\hline Amoxicillin/clavulanate + ciprofloxacin & 8 & $4.8 \%$ \\
\hline Amoxicillin/clavulanate + clarithromycin & 6 & $3.6 \%$ \\
\hline Meropenem & 5 & $3.0 \%$ \\
\hline Cefuroxime & 5 & $3.0 \%$ \\
\hline Other antibiotics or antibiotic combinations a & 66 & $39.3 \%$ \\
\hline
\end{tabular}

a e.g.: ceftriaxone (4 patients), flucloxacillin (3), amoxicillin (3), levofloxacin (3), ciprofloxacin + metronidazole (3), ciprofloxacin + rifampicin (2), cefepime (2), cefepime + tobramycin (2), clindamycin (2), trimethoprim/sulfamethoxazole (2), imipenem/cilastatin (2), vancomycin (2), ceftriaxone + rifampicin (2), cefuroxime + clarithromycin (2).

broad spectrum. Finally, IV) we identified risk factors for inadequate empirical antibiotic treatment, such as female sex or renal failure.

\section{I) Antibiotic utilization rate}

We found that $19.4 \%$ of medical and surgical patients admitted through the emergency department to a Swiss university hospital are started on therapeutic antibiotics within 24 hours of admission. This antibiotic utilization rate is similar to rates reported for medical admissions to an Acute Medicines Assessment Unit in Aberdeen, Scotland $(17 \%)[8]$, and to the prevalence of in-patients treated with antibiotics in a Norwegian university hospital (16.6\%) [17] and in 8 Swiss non-university hospitals (25\%) [9]. Higher antibiotic utilization rates (45.5\%) have been previously reported for example from Italian hospitals [18]. However, $84 \%$ of patients started on antibiotics in the present study received them in intravenous form, compared to $60 \%$ of patients in the Aberdeen study [8].

\section{II) Inadequacy of antibiotic therapies}

The empirical antibiotic therapy was inadequate in $22.4 \%$ of our patients. The rate of inadequate treatments among adjusted antibiotic therapies was even higher: $27.4 \%$.
These inadequacy rates compare favourably with published data indicating that as many as $41 \%$ to $91 \%$ of all antibiotic prescriptions in hospitals are inappropriate [11]. In the Aberdeen study for example, empirical therapy was in accordance with the hospital's antibiotic policy in only $52 \%$ of patients [8]. In a recent study in a 650-bed hospital in Cleveland, Ohio, 30\% of days of antibiotic therapy were deemed unnecessary [7]. Finally, the study examining the rate of inappropriate antibiotic use at 8 medium-sized Swiss hospitals found that $47 \%$ of patients not seen by infectious disease consultants had inappropriate antibiotic treatment [9].

Thus, inadequate use of antibiotics in our patients does not appear to be more frequent than at other institutions, despite the fact that no restrictive measures regarding antibiotic use are in place at our hospital. The relatively low rate of inadequate antibiotic therapies in this study might be explained by several factors. On one hand, patients on antibiotic prophylaxis were excluded from the present study, and inadequacy rates for antibiotic prophylaxis are frequently higher than for therapy [9]. On the other hand, differences in the populations studied and in hospital's characteristics may play a role. In this sense, three characteristics of our hospital may be relevant: first, an infectious 
Table 3: Reasons for inadequacy of empirical and adjusted antibiotic therapies

\begin{tabular}{lcc}
\hline Reason for inadequacy a & Number of patients & $\%$ \\
\hline Empirical antibiotic therapies & 539 & $100 \%$ \\
Inadequate empirical therapy & 121 & $24.0 \%$ \\
Spectrum too broad & 29 & $23.1 \%$ \\
Inadequate duration & 28 & $22.3 \%$ \\
Insufficient dosage & 27 & $18.2 \%$ \\
Spectrum too narrow & 22 & $17.4 \%$ \\
Wrong spectrum/inadequate use b & 21 & $2.5 \%$ \\
Excessive dosage & 3 & $100 \%$ \\
Adjusted antibiotic therapies & 168 & $52.2 \%$ \\
Inadequate adjusted therapy & 46 & $26.1 \%$ \\
Spectrum too broad & 24 & $15.2 \%$ \\
Wrong spectrum/inadequate use c & 12 & $4.4 \%$ \\
Insufficient dosage & 7 & $2.2 \%$ \\
Inadequate duration & 2 & $2.2 \%$ \\
Excessive dosage & 1 & \\
Spectrum too narrow & 1 & \\
\hline
\end{tabular}

a More than one reason may apply for each patient.

b If antibiotic given covered completely different spectrum than expected bacteria would require or no antibiotic therapy was warranted.

c If bacteriological results had shown that identified bacteria were resistant to antibiotics used, or antibiotic covered completely different spectrum

than expected bacteria would require or no antibiotic therapy was warranted.

diseases consultation service which has access to all wards of the hospital and which provides consultations with an "academic detailing" approach (each consultation is discussed in a direct conversation with the intern or resident in charge, providing a targeted one-on-one education) ; second, a close collaboration between infectious diseases department and microbiology laboratory (e.g. one microbiologist participates in the daily meeting of the infectious diseases department, where all patients seen by the infectious diseases consultants are discussed and all positive blood cultures are reviewed); and third, the clinical liaison between laboratory and ward through the infectious diseases consultants, who follow-up all positive blood cultures contacting the physicians in charge on the ward and providing oral clinical advice and, if requested, written consultation. Indeed, each one of these interventions has been shown to improve the use of antibiotics $[13,19,20]$.

\section{III) Reasons for inadequate adjusted therapies}

Despite the interventions mentioned above, the rate of inadequate adjusted therapies in our study was even higher than the rate of inadequate empirical therapies. The main reason for inadequacy of adjusted therapies was the unnecessary use of broad-spectrum antibiotics. This happened frequently because persistent fever after only 24 to 48 hours of empirical antibiotic therapy was considered to be caused by resistant bacteria, and empirical antibiotics were unnecessarily switched to broad-spectrum antibiotics. The second most common reason for inadequacy was the use of antibiotics that were ineffective against iso- lated pathogenic bacteria or bacteria to be expected according to the identified focus of infection, or the continuation of antibiotic therapy even after an infection was ruled out by negative culture results (e.g. in the case of postulated urinary tract infections). The failure to adapt therapy to culture results suggests that microbiological investigations had an insufficient impact on the management of patients. A similar problem was observed in the Aberdeen study, where in 55\% of patients with clinically significant culture results and an inappropriate empirical regimen, the medication was not changed to a more appropriate antibiotic [8]. Furthermore, researchers at the University of Iowa Hospitals and Clinics have previously shown that the reporting of antibiotic susceptibility testing data of positive blood cultures had only a limited impact on antimicrobial management of patients with bloodstream infections [21]. These observations confirm that the reassessment of empirical therapy after 2-4 days, when most culture results are available and clinical evolution is assessable, is crucial. Counselling of prescribers at this stage appears to be essential and is more likely to be efficacious than at an earlier stage [22,23].

\section{IV) Risk factors for inadequate therapy}

Most factors identified in the present study by multivariate analysis as being associated with adequate or inadequate antibiotic therapy are not surprising. Antibiotic therapy was more frequently inadequate in patients with renal failure (mainly because of difficulties in establishing the correct dose), and in patients where no infectious disease was identified or postulated (and where antibiotics 
Table 4: Characteristics of patients receiving adequate or inadequate empirical antibiotic treatment (univariate analysis).

\begin{tabular}{|c|c|c|c|c|}
\hline Characteristic & $\begin{array}{l}\text { Patients }(n) \text { receiving } \\
\text { adequate empirical } \\
\text { antibiotic treatment }\end{array}$ & $\begin{array}{l}\text { Patients }(n) \text { receiving } \\
\text { inadequate empirical } \\
\text { antibiotic treatment }\end{array}$ & $\mathrm{P}$-value & $\begin{array}{c}\text { OR }(95 \% \mathrm{Cl}) \text { for adequate } \\
\text { therapy }\end{array}$ \\
\hline Number of patients & $418(77.6 \%)$ & 121 (22.4\%) & & \\
\hline Women & 170 (70.2\%) & $72(29.8 \%)$ & $<0.001$ & $0.47(0.31-0.70)$ \\
\hline \multicolumn{5}{|l|}{ Age } \\
\hline Median age and range (years) & $67[18-100]$ & 72 [17-97] & $0.038 *$ & \\
\hline$<40$ years & $74(77.1 \%)$ & $22(22.9 \%)$ & 0.904 & $0.97(0.57-1.64)$ \\
\hline $41-60 y r$. & $91(87.5 \%)$ & $13(12.5 \%)$ & 0.007 & $2.31(1.12-4.30)$ \\
\hline$>60$ years & $253(74.6 \%)$ & $86(25.4 \%)$ & 0.034 & $0.62(0.40-0.97)$ \\
\hline \multicolumn{5}{|l|}{ Ward: } \\
\hline Medicine/Geriatrics & $28 \mid(78.3 \%)$ & $78(21.7 \%)$ & 0.399 & $1.19(0.80-1.76)$ \\
\hline Surgery & 135 (78.9\%) & $36(21.1 \%)$ & 0.733 & $1.09(0.70-1.65)$ \\
\hline Medical and surgical intensive care & 25 (71.4\%) & $10(28.6 \%)$ & 0.408 & $0.73(0.34-1.55)$ \\
\hline Neurology & I (25.0\%) & $3(75.0 \%)$ & $0.040 \dagger$ & $0.10(0.01-0.94)$ \\
\hline Died in hospital & $25(80.6 \%)$ & $6(19.4 \%)$ & 0.671 & $1.22(0.49-3.04)$ \\
\hline \multicolumn{5}{|l|}{ Charlson index: } \\
\hline Charlson index total 0 & $110(81.5 \%)$ & $25(18.5 \%)$ & 0.206 & $1.37(0.84-2.24)$ \\
\hline Charlson index total I - 5 & $264(75.9 \%)$ & $84(24.1 \%)$ & 0.205 & $0.76(0.49-1.17)$ \\
\hline Charlson index total > 5 & $44(78.6 \%)$ & $12(21.4 \%)$ & 0.845 & $1.07(0.55-2.10)$ \\
\hline \multicolumn{5}{|l|}{ McCabe index: } \\
\hline Not fatal & $343(77.4 \%)$ & $100(22.6 \%)$ & 0.882 & $0.96(0.56-1.64)$ \\
\hline Fatal (<5 years) & $52(81.3 \%)$ & $12(18.8 \%)$ & 0.450 & $1.29(0.67-2.51)$ \\
\hline Fatal (<6 months) & 23 (71.9\%) & $9(28.1 \%)$ & 0.428 & $0.73(0.33-1.61)$ \\
\hline \multicolumn{5}{|l|}{$\begin{array}{l}\text { Number of microbiological exams } \\
\text { performed: }\end{array}$} \\
\hline None & $78(77.2 \%)$ & $23(22.8 \%)$ & 0.931 & $0.98(0.58-1.64)$ \\
\hline One or more & $340(77.6 \%)$ & $98(22.4 \%)$ & 0.931 & $1.02(0.6 I-1.7 I)$ \\
\hline \multicolumn{5}{|l|}{ Infectious diseases consultants involved: } \\
\hline Within 24 hours & $23(62.2 \%)$ & $14(37.8 \%)$ & 0.020 & $0.45(0.22-0.89)$ \\
\hline Were involved & $58(69.0 \%)$ & $26(31.0 \%)$ & 0.042 & $0.59(0.35-0.99)$ \\
\hline Therapy adjusted & $128(76.2 \%)$ & $40(23.8 \%)$ & 0.611 & $0.89(0.58-1.38)$ \\
\hline Hepatic failure reported & I (50.0\%) & I (50.0\%) & $0.399 \dagger$ & $0.29(0.02-4.64)$ \\
\hline Renal failure reported & $100(69.0 \%)$ & 45 (31.0\%) & 0.004 & $0.53(0.35-0.82)$ \\
\hline $\begin{array}{l}\text { Received broad-spectrum antibiotics or } \\
\text { vancomycin }\end{array}$ & $62(65.3 \%)$ & $33(34.7 \%)$ & 0.002 & $0.46(0.29-0.75)$ \\
\hline Allergy to antibiotics reported & $29(70.1 \%)$ & $12(29.9 \%)$ & 0.276 & $0.68(0.33-1.37)$ \\
\hline \multicolumn{5}{|l|}{ Diagnoses } \\
\hline Biliary tract infections & $19(76.0 \%)$ & $6(24 \%)$ & 0.849 & $0.91(0.36-2.34)$ \\
\hline Bone and joint infections & $12(70.6 \%)$ & $5(29.4 \%)$ & $0.553 \dagger$ & $0.69(0.24-1.99)$ \\
\hline Central nervous system infections & $9(81.8 \%)$ & $2(18.1 \%)$ & $1.000 \dagger$ & $1.31(0.28-6.14)$ \\
\hline Ear, nose and throat infections & II (73.3\%) & $4(26.7 \%)$ & $0.753 \dagger$ & $0.79(0.25-2.53)$ \\
\hline Gastrointestinal infections & $59(73.8 \%)$ & $21(26.3 \%)$ & 0.377 & $0.78(0.45-1.35)$ \\
\hline Neutropenic fever & $10(100 \%)$ & $0(0.00 \%)$ & $0.127 \dagger$ & $\mathrm{N} / \mathrm{A}$ \\
\hline No infectious disease & I $(25.0 \%)$ & $3(75.0 \%)$ & $0.037 \dagger$ & $0.09(0.01-0.92)$ \\
\hline Respiratory tract infections & $139(82.2 \%)$ & $30(17.8 \%)$ & 0.077 & $1.51(0.95-2.39)$ \\
\hline Sepsis & 19 (86.4\%) & $3(13.6 \%)$ & $0.436 \dagger$ & $1.87(0.55-6.44)$ \\
\hline Skin and soft tissue infections & $48(81.4 \%)$ & $11(18.6 \%)$ & 0.458 & $1.30(0.65-2.58)$ \\
\hline $\begin{array}{l}\text { Suspected systemic infections without } \\
\text { identified focus }\end{array}$ & $19(76.0 \%)$ & $6(24.0 \%)$ & 0.849 & $0.91(0.36-2.34)$ \\
\hline $\begin{array}{l}\text { Urinary tract infections, prostatitis, } \\
\text { epididimytis }\end{array}$ & $83(73.5 \%)$ & $30(26.6 \%)$ & 0.240 & $0.75(0.47-1.21)$ \\
\hline Other & II (68.8\%) & 5 (31.3\%) & $0.371+$ & $1.30(0.21-1.84)$ \\
\hline SIRS present & 199 (77.7\%) & $57(22.3 \%)$ & 0.923 & $1.02(0.68-1.53)$ \\
\hline
\end{tabular}

Note: The adequacy of treatment was compared against the individual variables with the Chi-squared test with odds ratio production

* Wilcoxon-Mann-Whitney test

† Fisher's Exact test 
Table 5: Characteristics of patients receiving adequate or inadequate adjusted antibiotic treatment (univariate analysis)

\begin{tabular}{|c|c|c|c|c|}
\hline Characteristic & $\begin{array}{l}\text { Patients }(n) \text { receiving } \\
\text { adequate adjusted } \\
\text { antibiotic treatment }\end{array}$ & $\begin{array}{l}\text { Patients }(n) \text { receiving } \\
\text { inadequate adjusted } \\
\text { antibiotic treatment }\end{array}$ & $\mathrm{p}$-value & $\begin{array}{c}\text { OR }(95 \% \mathrm{Cl}) \text { for adequate } \\
\text { therapy }\end{array}$ \\
\hline Number of patients & $121(72.5 \%)$ & $46(27.5 \%)$ & & \\
\hline Women & $54(70.1 \%)$ & $23(29.9 \%)$ & 0.534 & $0.8 \mathrm{I}(0.4 \mathrm{I}-\mathrm{I} .59)$ \\
\hline \multicolumn{5}{|l|}{ Age } \\
\hline Median age and range (years) & 65 [2I-97] & 70 [19-95] & $0.115^{*}$ & \\
\hline$<40$ & $22(78.6 \%)$ & $6(21.4 \%)$ & 0.427 & $1.48(0.56-3.93)$ \\
\hline $41-60$ & $29(80.6 \%)$ & 7 (19.4\%) & 0.219 & $1.76(0.7 \mathrm{I}-4.35)$ \\
\hline$>60$ & $70(68.0 \%)$ & $33(32.0 \%)$ & 0.099 & $0.54(0.26-1.13)$ \\
\hline \multicolumn{5}{|l|}{ Ward: } \\
\hline Medicine/Geriatrics & $85(72.0 \%)$ & $33(28.0 \%)$ & 0.472 & $0.77(0.38-1.56)$ \\
\hline Surgery & 36 (73.5\%) & $13(26.5 \%)$ & 0.955 & $0.98(0.47-2.06)$ \\
\hline Medical and surgical intensive care & $13(86.7 \%)$ & $2(13.3 \%)$ & $0.360 \dagger$ & $2.45(0.53-11.28)$ \\
\hline Neurology & $0(0.0 \%)$ & $0(0.0 \%)$ & $N / A$ & $\mathrm{~N} / \mathrm{A}$ \\
\hline Died in hospital & $10(90.9 \%)$ & I (9.1\%) & $0.293 \dagger$ & $4.05(0.50-32.60)$ \\
\hline \multicolumn{5}{|l|}{ Reason for switch: } \\
\hline Switch due to bacterial lab results & $58(89.2 \%)$ & 7 (10.7\%) & $<0.001$ & $5.13(2.13-12.37)$ \\
\hline Switch due to other reason & $43(64.2 \%)$ & $24(35.8 \%)$ & 0.050 & $0.51(0.25-1.01)$ \\
\hline \multicolumn{5}{|l|}{ Charlson Index: } \\
\hline Charlson index total 0 & $26(76.5 \%)$ & 8 (23.5\%) & 0.557 & $1.30(0.54-3.13)$ \\
\hline Charlson index total I - 5 & $84(71.8 \%)$ & $33(28.2 \%)$ & 0.770 & $0.89(0.42-1.89)$ \\
\hline Charlson index total $>5$ & $11(68.8 \%)$ & $5(31.2 \%)$ & $0.771 \dagger$ & $0.82(0.27-2.50)$ \\
\hline \multicolumn{5}{|l|}{ McCabe index } \\
\hline Not fatal & 97 (74.0\%) & $34(26.0 \%)$ & 0.380 & $1.43(0.64-3.16)$ \\
\hline Fatal (<5 years) & $18(75.0 \%)$ & $6(25.0 \%)$ & 0.763 & $1.17(0.43-3.15)$ \\
\hline Fatal (<6 months) & $6(50.0 \%)$ & $6(50.0 \%)$ & $0.055 \dagger$ & $0.35(0.11-1.14)$ \\
\hline \multicolumn{5}{|l|}{$\begin{array}{l}\text { Number of microbiological exams } \\
\text { performed: }\end{array}$} \\
\hline None & $13(76.5 \%)$ & $4(23.5 \%)$ & $0.783 \dagger$ & $1.26(0.39-4.10)$ \\
\hline One or more & $108(72 \%)$ & $42(28 \%)$ & $0.783 \dagger$ & $0.79(0.24-2.57)$ \\
\hline \multicolumn{5}{|l|}{ Infectious diseases consultants involved: } \\
\hline Within 24 hours & $22(88.0 \%)$ & $3(12.0 \%)$ & 0.059 & $3.19(0.91-11.21)$ \\
\hline Were involved & $52(82.5 \%)$ & $11(17.5 \%)$ & 0.023 & $2.40(1.11-5.16)$ \\
\hline Hepatic failure reported & I (100.0\%) & $0(0.0 \%)$ & $1.000 \dagger$ & N/A \\
\hline Renal failure reported & $34(70.8 \%)$ & $14(29.2 \%)$ & 0.766 & $0.89(0.43-1.88)$ \\
\hline $\begin{array}{l}\text { Received broad-spectrum antibiotics or } \\
\text { vancomycin }\end{array}$ & 37 (84.1\%) & 7 (I5.9\%) & 0.520 & $1.28(0.60-2.72)$ \\
\hline Allergy to antibiotics reported & $9(64.3 \%)$ & $5(35.7 \%)$ & $0.534 \dagger$ & $0.66(0.21-2.08)$ \\
\hline \multicolumn{5}{|l|}{ Diagnoses } \\
\hline Biliary tract infections & $5(83.3 \%)$ & I (I6.7\%) & $1.000 \dagger$ & $1.94(0.22-17.06)$ \\
\hline Bone and joint infections & $10(100.0 \%)$ & $0(0.0 \%)$ & $0.063 \dagger$ & N/A \\
\hline CNS infections & $3(100.0 \%)$ & $0(0.0 \%)$ & $0.562 \dagger$ & $\mathrm{N} / \mathrm{A}$ \\
\hline Ear, nose and throat infections & $0(0.00 \%)$ & $\mathrm{I}(100 \%)$ & $0.275 \dagger$ & $\mathrm{N} / \mathrm{A}$ \\
\hline Gastrointestinal infections & $17(63.0 \%)$ & $10(37.0 \%)$ & 0.228 & $0.59(0.25-1.40)$ \\
\hline $\begin{array}{l}\text { Urinary tract infections, postatitis, } \\
\text { epididimytis }\end{array}$ & $21(67.7 \%)$ & $10(32.3 \%)$ & 0.52 & $0.76(0.33-1.76)$ \\
\hline Neutropenic fever & $6(85.7 \%)$ & I (14.3\%) & $0.675 \dagger$ & $2.35(0.28-20.05)$ \\
\hline Respiratory tract infections & $34(60.7 \%)$ & $22(39.3 \%)$ & 0.016 & $0.43(0.21-0.86)$ \\
\hline Sepsis & $12(92.3 \%)$ & I (7.7\%) & $0.116 \dagger$ & $4.95(0.63-39.24)$ \\
\hline Skin and soft tissue infections & $10(71.4 \%)$ & $4(28.6 \%)$ & $1.000 \dagger$ & $0.95(0.28-3.18)$ \\
\hline $\begin{array}{l}\text { Suspected systemic infections without } \\
\text { identified focus }\end{array}$ & $5(71.4 \%)$ & $2(28.6 \%)$ & $1.000 \dagger$ & $0.95(0.18-5.07)$ \\
\hline Other & $8(88.9 \%)$ & I (II.I\%) & $0.447 \dagger$ & $3.19(0.39-26.21)$ \\
\hline
\end{tabular}

\footnotetext{
* Wilcoxon-Mann-Whitney test
}

† Fisher's Exact test 
were usually started only because of fever). In contrast, a change of antibiotic therapy according to results of microbiological investigations was associated with adequate therapy. The association between use of broad-spectrum antibiotics or vancomycin and inadequate empirical therapy confirms that the use of these medications is often unjustified. It is more difficult to explain why women were less likely to receive adequate empirical antibiotic treatment than men. Gender differences in the prescription of treatment or prophylaxis have previously been reported, e.g. for cardiovascular diseases and HIV-infection [24-27]. To our knowledge however, only one previous study reported that rates of antibiotic use were influenced by gender (females in one New Zealand town received antibiotics more often than males) [28]. This study found also a strong relationship between socioeconomic status and antibiotic dispensing. In our study, women were slightly older than men (mean age \pm standard deviation: $65.5 \pm 20.4$ years, versus $62.3 \pm 19.6$ ), and age over 60 years was associated with inadequate empirical antibiotic treatment in univariate analysis. We cannot speculate on the role of socioeconomic status, since we did not collect information on this factor.

The impact of infectious diseases consultations was considered by recording whether infectious diseases consultants were involved within 24 hours of admission or whether they were involved at all. In the univariate analysis involvement of infectious diseases consultants was significantly associated with inadequate empirical therapy (Tab. 4). This can be explained by the fact that consultation is usually required for patients with more severe or difficult to manage infections or with unclear clinical presentation, who are usually started on empirical antibiotic therapy before the infectious diseases consultation is obtained, in order to avoid delays. Thus, adjusted therapies may show more reliably what the effect of infectious diseases consultations was. Indeed, involvement of infectious diseases consultants was associated with adequate adjusted therapy (Tab. 5) in univariate analysis.

The present study has several limitations. In particular, patients started on antibiotics more than 24 hours after admission or who received only antibiotic prophylaxis, patients admitted directly to the wards, and patients who received therapeutic oral antibiotics as out-patients were not included in the study. In addition, only surgical, medical, geriatric, and neurological patients were evaluated. Also, we did not investigate the relationship between adequacy or inadequacy of treatment and clinical outcomes other than in-hospital death. However, this study has also several strengths. Clinical data were raised and evaluated consistently and prospectively in a large defined patient population, and patients were followed until discharge. Furthermore, a large part of in-patients at our hospital, as at other hospitals, are admitted through the emergency department. Hence, our results are clinically relevant for this setting.

\section{Conclusion}

In conclusion, despite the absence of a restrictive antibiotic policy, the rate of inadequate antibiotic therapies at our hospital was similar to rates reported from other institutions. This suggests that restrictions in the antibiotic use are not an absolutely necessary component of an antibiotic stewardship approach based mainly on multidisciplinary collaboration, education and close clinical liaison with the bacteriology laboratory. Nevertheless, the present study demonstrated a significant overuse of antibiotics, especially broad-spectrum antibiotics and intravenous antibiotics, and an insufficient consideration of microbiological results. Surprisingly, adjusted antibiotic therapies were more frequently inappropriate than empirical therapies. Thus, interventions aiming at improving antibiotic prescribing should focus on both initial empirical therapy and streamlining and adjustment of therapy. Furthermore, the impact of microbiological results on the clinical management of patients should be improved.

\section{Competing interests}

The author(s) declare that they have no competing interests.

\section{Authors' contributions}

JM followed up all patients admitted through the Emergency Department, identified all patients qualifying for the study, prospectively collected the information on each patient, reviewed each patients' chart and drafted the manuscript. JM and SB reviewed together each case report form with the corresponding chart to assess the adequacy of the antibiotic therapy. SB conceived of the study and helped to draft the manuscript. MS and PS performed the statistical analysis. All authors participated in the design of the study, helped to interpret the data and to draft the manuscript. All authors read and approved the final manuscript.

\section{Financial Support}

Bristol-Myers Squibb GmbH, Merck Sharp \& Dohme-Chibret AG, GlaxoSmithKline AG, AstraZeneca AG, Wyeth Pharmaceuticals AG, Bayer (Schweiz) AG, Pfizer AG. S.B. was supported by a grant from the Department of Internal Medicine (VFWAWF), University Hospital Basel, Basel, Switzerland.

This study was presented in part at the $15^{\text {th }}$ European Congress of Clinical Microbiology and Infectious Diseases, Copenhagen, Denmark, 2-5 April 2005, Abstract O58. 


\section{Acknowledgements}

We are indebted to $M$. Dangel, MPH, and H. Drechsler, MD (Division of Infectious Diseases \& Hospital Epidemiology, University Hospital Basel) for technical assistance, and to J. Pettypool for help in editing the manuscript.

\section{References}

I. Mera RM, Miller LA, Daniels JJ, Weil JG, White AR: Increasing prevalence of multidrug-resistant Streptococcus pneumoniae in the United States over a I0-year period: Alexander Project. Diagn Microbiol Infect Dis 2005, 5 I: 195-200.

2. Bratu S, Landman D, Haag R, Recco R, Eramo A, Alam M, Quale J: Rapid spread of carbapenem-resistant Klebsiella pneumoniae in New York City: a new threat to our antibiotic armamentarium. Arch Intern Med 2005, 165:| 1430-1435

3. Oteo J, Lazaro E, de Abajo FJ, Baquero F, Campos J: Antimicrobialresistant invasive Escherichia coli, Spain. Emerg Infect Dis 2005, I I:546-553.

4. Gould IM: Antibiotic policies and control of resistance. Curr Opin Infect Dis 2002, 15:395-400.

5. Neuhauser MM, Weinstein RA, Rydman R, Danziger LH, Karam G, Quinn JP: Antibiotic resistance among gram-negative bacilli in US intensive care units: implications for fluoroquinolone use. Jama 2003, 289:885-888.

6. (WHO) WHO: Hospitals: recommendations for intervention. WHO global strategy for containment of antimicrobia resistance. Geneva, Switzerland, WHO; 200I:26-35.

7. Hecker MT, Aron DC, Patel NP, Lehmann MK, Donskey CJ: Unnecessary use of antimicrobials in hospitalized patients: current patterns of misuse with an emphasis on the antianaerobic spectrum of activity. Arch Intern Med 2003, 163:972-978.

8. Kumarasamy Y, Cadwgan T, Gillanders IA, Jappy B, Laing R, Gould IM: Optimizing antibiotic therapy-the Aberdeen experience. Clin Microbiol Infect 2003, 9:406-4II.

9. Bugnon-Reber A, de Torrente A, Troillet N, Genne D: Antibiotic misuse in medium-sized Swiss hospitals. Swiss Med Wkly 2004, 134:481-485.

10. Erbay A, Colpan A, Bodur H, Cevik MA, Samore MH, Ergonul O: Evaluation of antibiotic use in a hospital with an antibiotic restriction policy. Int J Antimicrob Agents 2003, 21:308-312.

II. Hogerzeil HV: Promoting rational prescribing: an international perspective. Br J Clin Pharmacol 1995, 39: I-6.

12. Brown EM: Interventions to optimise antibiotic prescribing in hospitals: the UK approach. In Antibiotic policies: theory and practice Edited by: Gould IM and Meer JWM. New York, Kluwer Academic Plenum Publishers; 2005:159-183.

13. Solomon DH, Van Houten L, Glynn RJ, Baden L, Curtis K, Schrager $\mathrm{H}$, Avorn J: Academic detailing to improve use of broad-spectrum antibiotics at an academic medical center. Arch Intern Med 2001, 16I:1897-1902.

14. Ruttimann S, Keck B, Hartmeier C, Maetzel A, Bucher HC: Longterm antibiotic cost savings from a comprehensive intervention program in a medical department of a university-affiliated teaching hospital. Clin Infect Dis 2004, 38:348-356.

15. Charlson ME, Pompei P, Ales KL, MacKenzie CR: A new method of classifying prognostic comorbidity in longitudinal studies: development and validation. Journal of Chronic Diseases 1987, 40:373-383.

16. McCabe WR JGG: Gram-negative bacteremia: I Etiology and ecology. Arch Intern Med 1962, I I 0:847-855.

17. Berild D, Ringertz SH, Lelek M: Appropriate antibiotic use according to diagnoses and bacteriological findings: report of 12 point-prevalence studies on antibiotic use in a university hospital. Scand J Infect Dis 2002, 34:56-60.

18. Porretta A, Giuliani L, Vegni FE, Larosa M, Privitera G: Prevalence and patterns of antibiotic prescribing in Italian hospitals. Infection 2003, 31 Suppl 2:16-21.

19. Bouza E, Sousa D, Munoz P, Rodriguez-Creixems M, Fron C, Lechuz JG: Bloodstream infections: a trial of the impact of different methods of reporting positive blood culture results. Clin Infect Dis 2004, 39: II6I-II69.

20. Cunney RJ, McNamara EB, Alansari N, Loo B, Smyth EG: The impact of blood culture reporting and clinical liaison on the empiric treatment of bacteraemia. J Clin Pathol 1997, 50:1010-1012.
21. Munson EL, Diekema DJ, Beekmann SE, Chapin KC, Doern GV: Detection and treatment of bloodstream infection: laboratory reporting and antimicrobial management. J Clin Microbiol 2003, $41: 495-497$.

22. Thuong M, Shortgen F, Zazempa V, Girou E, Soussy CJ, Brun-Buisson C: Appropriate use of restricted antimicrobial agents in hospitals: the importance of empirical therapy and assisted reevaluation. J Antimicrob Chemother 2000, 46:50I-508.

23. Senn L, Burnand B, Francioli P, Zanetti G: Improving appropriateness of antibiotic therapy: randomized trial of an intervention to foster reassessment of prescription after 3 days. J Antimicrob Chemother 2004, 53:1062-1067.

24. Heer T, Schiele R, Schneider S, Gitt AK, Wienbergen H, Gottwik M, Gieseler U, Voigtlander T, Hauptmann KE, Wagner S, Senges J: Gender differences in acute myocardial infarction in the era of reperfusion (the MITRA registry). Am J Cardiol 2002, 89:5II-5I7.

25. Kucher N, Tapson VF, Quiroz R, Mir SS, Morrison RB, McKenzie D, Goldhaber SZ: Gender differences in the administration of prophylaxis to prevent deep venous thrombosis. Thromb Haemost 2005, 93:284-288

26. Ferrara A, Williamson DF, Karter AJ, Thompson TJ, Kim C: Sex differences in quality of health care related to ischemic heart disease prevention in patients with diabetes: the translating research into action for Diabetes (TRIAD) study, 2000-200 I. Diabetes Care 2004, 27:2974-2976.

27. Gebo KA, Fleishman JA, Conviser R, Reilly ED, Korthuis PT, Moore RD, Hellinger J, Keiser P, Rubin HR, Crane L, Hellinger FJ, Mathews WC: Racial and gender disparities in receipt of highly active antiretroviral therapy persist in a multistate sample of HIV patients in 200 I. J Acquir Immune Defic Syndr 2005, 38:96- I03.

28. Norris P, Becket G, Ecke D: Demographic variation in the use of antibiotics in a New Zealand town. N Z Med J 2005, I I 8:UI352.

\section{Pre-publication history}

The pre-publication history for this paper can be accessed here:

http://www.biomedcentral.com/1471-2334/7/21/prepub
Publish with Biomed Central and every scientist can read your work free of charge

"BioMed Central will be the most significant development for disseminating the results of biomedical research in our lifetime."

Sir Paul Nurse, Cancer Research UK

Your research papers will be:

- available free of charge to the entire biomedical community

- peer reviewed and published immediately upon acceptance

- cited in PubMed and archived on PubMed Central

- yours - you keep the copyright
BioMedcentral 